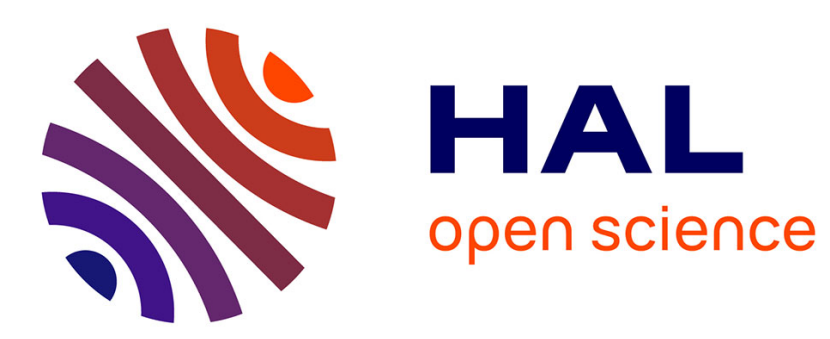

\title{
From Climate to Biodiversity - Procedural transcriptions and innovations within IPBES in the light of IPCC practices
}

Guillaume Futhazar

\section{- To cite this version:}

Guillaume Futhazar. From Climate to Biodiversity - Procedural transcriptions and innovations within IPBES in the light of IPCC practices. The Intergovernmental Platform on Biodiversity and Ecosystem Services (IPBES) Meeting the challenge of biodiversity conservation and governance, Routledge , 2016, 978-1-138-12125-6 (rel.). halshs-01477952

\section{HAL Id: halshs-01477952}

https://shs.hal.science/halshs-01477952

Submitted on 27 Feb 2017

HAL is a multi-disciplinary open access archive for the deposit and dissemination of scientific research documents, whether they are published or not. The documents may come from teaching and research institutions in France or abroad, or from public or private research centers.
L'archive ouverte pluridisciplinaire HAL, est destinée au dépôt et à la diffusion de documents scientifiques de niveau recherche, publiés ou non, émanant des établissements d'enseignement et de recherche français ou étrangers, des laboratoires publics ou privés. 


\section{From Climate to Biodiversity -}

\section{Procedural transcriptions and innovations within IPBES in the}

\section{light of IPCC practices}

by Guillaume Futhazar*

Ph.D Candidate on Contract, Aix-Marseille University

\footnotetext{
* $\mathrm{PhD}$ candidate on contract for Labex OT-MED (ANR-11-LABX-0061) under the supervision of CERIC (CERIC-CNRS UMR 7318, Aix Marseille University, France).

This chapter is a contribution to the CIRCULEX project (ANR-12-GLOB-0001-03 CIRCULEX), funded by the French National Research Agency, which is devoted to studying the circulation of international environmental governance norms and actors.
} 
Describing IPBES ${ }^{1}$ as simply an 'IPCC ${ }^{2}$ for biodiversity' would be overly simplistic. Indeed, these two institutions have major differences that have been underlined on several occasions ${ }^{3}$. These differences are the result of fundamental structuring aspects: the respective themes of these institutions, the institutional context surrounding their establishment and their mandate.

Concerning their themes, it is no longer necessary nowadays to engage in a lengthy demonstration to illustrate that climate and biodiversity ${ }^{4}$ are facing major crises that call for swift and global responses. However, although climate change is the prime example of a global crisis, biodiversity constitutes an element that is intrinsically linked to territories as each region has to deal with specific yet connected threats. Moreover, biodiversity is not uniformly distributed among territories. Some countries, known as 'mega-diverse', have a higher degree of biological diversity and a vast majority of these are developing countries. As such, we can see through this notion the resurgence of the South/North divide in environmental debates. This strong link between biodiversity and territories also allows for a salient influence of the concept of permanent sovereignty over natural resources. Debates and negotiations for the establishment of the IPBES Platform and within its fora are clearly heavily influenced by these eminently political and legal considerations.

IPBES and IPCC were negotiated and established in very different institutional contexts. IPCC was founded prior to the adoption of the United Nation Framework Convention for Climate Change $^{5}$ and it even took part in discussions that lead to the Convention's adoption ${ }^{6}$, whereas

\footnotetext{
Intergovernmental Platform on Biodiversity and Ecosystem Services.

Inergovernmental Panel on Climate Change.

See Brooks, T.M., Lamoreux, J.F., Soberon, J., 'IPBES $\neq I P C C$ ', Trends in ecology and evolution, vol. 29 , $\mathrm{n}^{\circ}$ 10, 2014, pp. 543-545; Maljean-Dubois S. 'La Plateforme Intergouvernementale Scientifique et Politique sur la Biodiversité et les Services Ecosystémiques (IPBES)', Journal International de Bioéthique, vol. 35, $\mathrm{n}^{\circ} 1$, 2014, pp. 55-73.

4 In the context of this chapter, we understand biodiversity as being 'the variability among living organisms from all sources' (article 2 of the Convention on Biological Diversity).

5 United Nations Framework Convention on Climate Change, New York, 21 March 1992, entered into force on June 9, 1994, U.N.T.S vol. 1771, p. 107.

6 Agrawala (S.), 'Structural and process history of the IPCC', Climate Change, vol. 39, 1998, pp. 621-642.
} 
IPBES has had to fit into in a very crowded institutional environment. Major conventions on biodiversity and ecosystems have existed for decades and constitute a regime complex, which is understood as being an accumulation of overlapping regimes with no hierarchy ${ }^{7}$ and various types of interaction ${ }^{8}$. Alongside to these conventions, several UN institutions are also actively working on this broad theme, most notably UNEP, UNDP, FAO and UNESCO (which are among the main IPBES partners). The establishment of IPBES therefore raises the necessary question of how it will interact with numerous actors of the system.

Finally, the IPBES mandate is not a simple reiteration of what IPCC does. Both IPCC and IPBES seek to periodically assess the state of knowledge for their respective themes, but IPBES goes further by providing innovative tools and advice for its members ${ }^{9}$. The Platform, based on its work on the different assessments, will produce a list of research priorities. It will also work on strengthening capacity building and identifying tools and methodologies for decision makers in order to achieve effective biodiversity governance. However, like IPCC, IPBES will not generate new knowledge on its own ${ }^{10}$.

These several major differences highlight the fact that we must abandon the idea that IPBES is only a duplication of the IPCC experience on a different topic. Still, it would be irrelevant to completely disconnect these two institutions as they are obviously interlinked. The intervention of the IPCC ex-Chair Rajendra Pachauri during the $3^{\text {rd }}$ IPBES Plenary is an illustration, among others, of the links between the two bodies. Climate and biodiversity are also connected

7 Rausitalia, K., Victor, D., 'The Regime Complex for Plant Genetic Ressources', International Organization, vol. 58, n², 2004, pp. 277-309.

8 Orsini, A., Morin, J.F., Young, O., 'Regime Complexes: A Buzz, a Boom, or a Boost for Global Governance?', Global Governance, vol. 19, 2013, pp. 27-39.

9 The detailed mandate of the IPBES is available on line: http://www.ipbes.net/policies-and-procedures.html (last accessed: 30/06/2015).

10 Functions, operating principles and institutional arrangements of the Intergovernmental Science-Policy Platform on Biodiversity and Ecosystem Services, p. 1, « The Platform [...] should not directly undertake new research» 
elements and the biodiversity crisis will not be halted if the climate crisis is not dealt with ${ }^{11}$. This situation has been underlined by the Millennium Ecosystem Assessment which demonstrated that climate change is one of the drivers of biodiversity loss and its impact will increase in the upcoming years ${ }^{12}$. Biodiversity is also a tool in the mitigation of climate change as healthy ecosystems can absorb carbon and reduce its accumulation in the atmosphere ${ }^{13}$. Moreover, negotiators involved in the discussion for the establishment of IPBES have been clearly influenced by IPCC's experience despite stressing the differences between the two initiatives. Overall, we can see a tendency within IPBES to simultaneously differentiate itself from its model while also reaffirming its evident ties.

The purpose of the present contribution it so study how this complex situation has impacted the IPBES rules of procedure by comparing them with those that prevail within the IPCC framework. However, prior to this analysis, it is essential to establish a precise definition of the term 'procedure' in the context of this study.

- What is a procedure?

Most legal research is focused on a specific definition of the concept of procedure, based on its contentious aspect. Procedures are usually understood as being the rules shaping the trial process. However, in the present chapter, our understanding of the term is broader and closer to the general definition - basically the steps to follow in order to accomplish a certain task or achieve a specific result ${ }^{14}$. As such, this definition concerns the functioning of institutions and

11 On this specific topic, IPCC produced a report in 2002 called 'Climate Change and Biodiversity', which can be accessed online at: www.ipcc.ch/publications_and_data/publications_and_data_technical_papers.shtml (last accessed: 30/06/2015).

12 Millennium Ecosystem Assessment, Ecosystem and Human Well Being, Synthesis, p. 2, available online at: www.millenniumassessment.org/documents/document.356.aspx.pdf (last accessed: 30/06/2015).

13 For more information on this topic, see: www.cbd.int/climate/intro.shtml (last accessed: 30/06/2015).

14 The Cambridge Online Dictionary gives the following definition: "the order or method of doing something". 
covers rules governing their internal functioning and shaping their activities. However, this definition does not provide any indication regarding the legal consequences of these procedures.

In the context of IPBES, a breach of the procedures would not have any legal consequences. Neither the rights nor the obligations of member states would be impacted by a procedural breach and no third party could be seized with this matter in order to pronounce sanctions. Yet, this absence of legal consequence does not imply that the application of these procedural rules is optional. The Platform and any other relevant actors playing a part in the process are bound by them and their application ensures that the activities and productions of the Platform are perceived as being legitimate. Indeed, rules of procedure are the product of state consensus with states being the only parties entitled to adopt them within the Platform Plenary ${ }^{15}$. As a consequence of the consensus requirement, the Platform Plenaries generated lengthy negotiations in order to lay down the procedural aspect of this new institution. The rules of procedure are therefore the expression of the member states' expectations on how the Platform must work. Any production or activity that would overstep the procedural framework would consequently be rejected by the members. In short, compliance with the agreed procedures is the necessary condition for the legitimacy of the IPBES process towards its members, with legitimacy being understood as what is perceived as being fair, equitable and politically acceptable ${ }^{16}$.

The procedures not only ensure the legitimacy of the activities and deliverables of the Platform towards the member states, they also do so towards stakeholders. Indeed, procedures as well as all of the IPBES institutional characteristics (mandate, structure, and work programme) tend to

15 Rules of Procedure for the Plenary of the Platform, Rule 36, available online at: www.ipbes.net/policies-andprocedures.html (last accessed: 30/06/2015).

16 Koetz, T., Farrell, K., Bridgewater, P., Building better science-policy interfaces for international environmental governance: assessing the potential within the IPBES, International Environmental Agreements: Politics, Law and Economics, vol. 12, n 1, 2012, pp. 1-21, p. 3. 
fulfill three main criteria ${ }^{17}:$ credibility $^{18}$, relevance ${ }^{19}$ and legitimacy. Therefore, this chapter also aims to determine whether the procedures of this young institution satisfy these principles.

In discussing the diffusion and adaptation of procedure from IPCC to IPBES, this chapter echoes the work of Alexander Ovodenko and Robert Keohane, who established a theoretical framework for institutional diffusion, which is understood as being, "the adoption in new or reformed institutions of institutional features already operating in other institutions, national, international or transnational" ${ }^{20}$. The authors identify two factors that must be taken into account when studying diffusion cases. The first factor is functional: an institutional characteristic, such as a rule of procedure, will be diffused if the two institutions face the same problem structure, have similar involved actors, and if the institutional characteristic being diffused is perceived as being successful ${ }^{21}$. However, this first factor is insufficient on its own to fully understand institutional diffusion and we must also take into account the political factor, which encompasses the different ideas, powers and interests coexisting within a system ${ }^{22}$. The two different sections of this chapter reflect these two factors. The first section illustrates the obvious influence IPCC has had on the establishment of the IPBES rules of procedure for functional reasons (I), and the second section highlights the procedural innovations of the Platform and attempts to explain them in the light of the Platform characteristics (II).

17 Functions, operating principles and institutional arrangements of the Intergovernmental Science-Policy Platform on Biodiversity and Ecosystem Services, p. 2, 'Be scientifically independent and ensure credibility, relevance and legitimacy through peer review of its work and transparency in its decision-making processes'.

18 Koetz, T., Farrell, K., Bridgewater, P., 'Building better science-policy interfaces for international environmental governance: assessing the potential within the IPBES', op.cit., p.3, "credibility reflects the perceived validity of information, methods and procedures provided and applied via a Science Policy Interface".

19 Idem, "relevance reflects the extent to which the work carried out within a SPI is responsive to the conditions and needs of the policy process".

20 Ovodenko, A., Keohane, R., 'Institutional diffusion in international environmental affairs', Institutional Affairs, vol. 88, n³, 2011, pp. 523-541, p. 524.

21 Ibid, p. 541.

22 Idem. 
Overall this chapter hopes to add to the debate concerning the linkages between IPCC and IPBES $^{23}$ by using, as a starting point, elements that are seldom the focus of detailed analysis: rules of procedure.

I - The influence of IPCC in the shaping of IPBES

During the lengthy discussions that led to the establishment of IPBES, one main argument was put forward on several occasions, i.e. that the Platform is not a simple reiteration of IPCC. During the Putrajaya meeting in 2008, the participants insisted on this aspect while also recognizing that IPCC could serve as a model in the debates on how to design the new institution ${ }^{24}$. This call for differentiation yet inspiration recurred at each meeting that addressed the creation of the Platform and even during the IPBES Plenary. For instance, during the Busan meeting in 2010, the fact that an information document on IPCC was distributed to the attendees is particularly significant as it illustrates the status of IPCC's experience in negotiators' minds ${ }^{25}$. This situation evidently led to several procedural transplantations from IPCC to IPBES. Firstly, the IPBES report drafting process (A) and secondly the conflict of interest policy (B).

\section{A) The IPBES report drafting process}

The IPCC report drafting process is the result of a slow process that began following its creation in the late $1980 \mathrm{~s}^{26}$. Several political factors led IPCC to further elaborate procedures that would ensure the highest possible credibility for its reports. As such, the transplantation of these procedures in the context of IPBES is clearly an asset for the Platform, which is able to benefit from the vast experience of IPCC in this field.

\footnotetext{
23 See Beck (S.) et al., 'Towards a reflexive turn in the governance of global environmental expertise: the case of the IPCC and the IPBES', Gaya, vol.23, n², 2014, pp. 80-87.

24 Earth Negotiation Bulletin (ENB), vol. 158, $\mathrm{n}^{\circ} 1,2008$.

$25 \mathrm{UNEP} / \mathrm{IPBES} / 3 / \mathrm{INF} / 5$, Background document on the Intergovernmental Panel on Climate Change.

26 Agrawala (S.), 'Structural and process history of the IPCC', op. cit.
} 
A close look at the procedures of both IPCC and IPBES shows how similar they are, even to the point where some dispositions appears to be clear 'copy/paste' of IPCC rules. For instance, the procedure for the incorporation of reviews, which aims to ensure greater credibility and scientific soundness, is a practically identical step for both organizations (see figure 1).

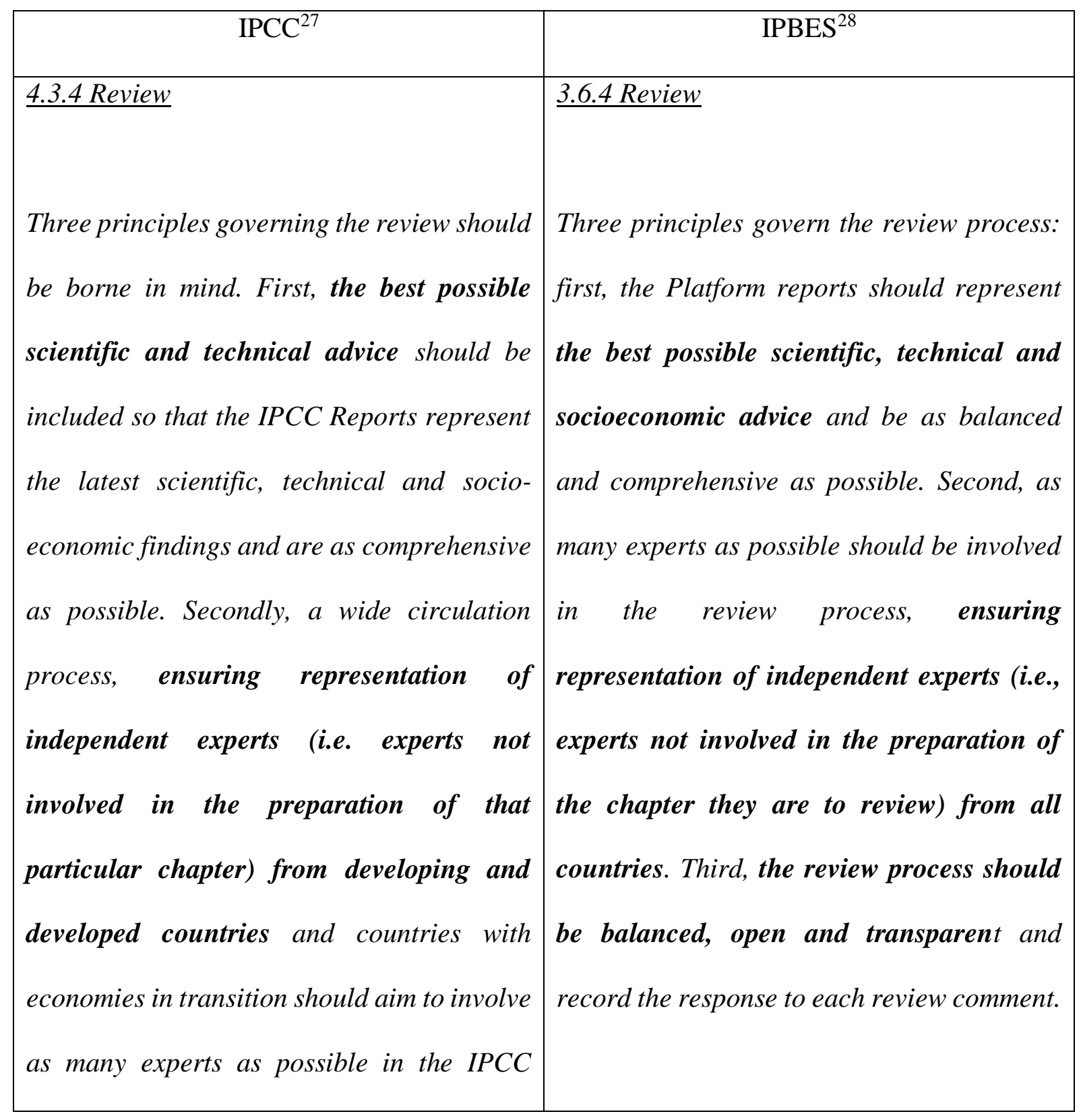

\footnotetext{
27 Appendix A to the Principles Governing IPCC Work, Procedures for the preparation, review, acceptance, adoption approval and publication of IPCC reports, online at: www.ipcc.ch/organization/organization_procedures.shtml (last accessed: 30/06/2015).

28 IPBES/3/L.2, Procedures for the preparation of Platform deliverables.
} 
process. Thirdly, the review process should

be objective, open and transparent.

Figure 1: Comparison of procedures for the incorporation of comments in the drafting of

$\underline{\text { IPBES and IPCC reports. }}$

This comparison could be made for several aspects of the drafting procedures, thus showing how the IPCC precedent has had a huge influence in the conceptualization of the Platform procedures. Obviously, aspects calling for adaption because of the Platform's specificity have been modified accordingly, but nevertheless there is clearly a high degree of similarity in the way both institutions produce their reports (as illustrated in figure 2).

This transplantation is a token of credibility for the Platform. IPCC procedures have undergone the test of time and controversies, and they guarantee the current status of the Panel as a major scientific actor in the field of climate change. Hence, it can be hoped that this credibility will be as strong for the Platform. 

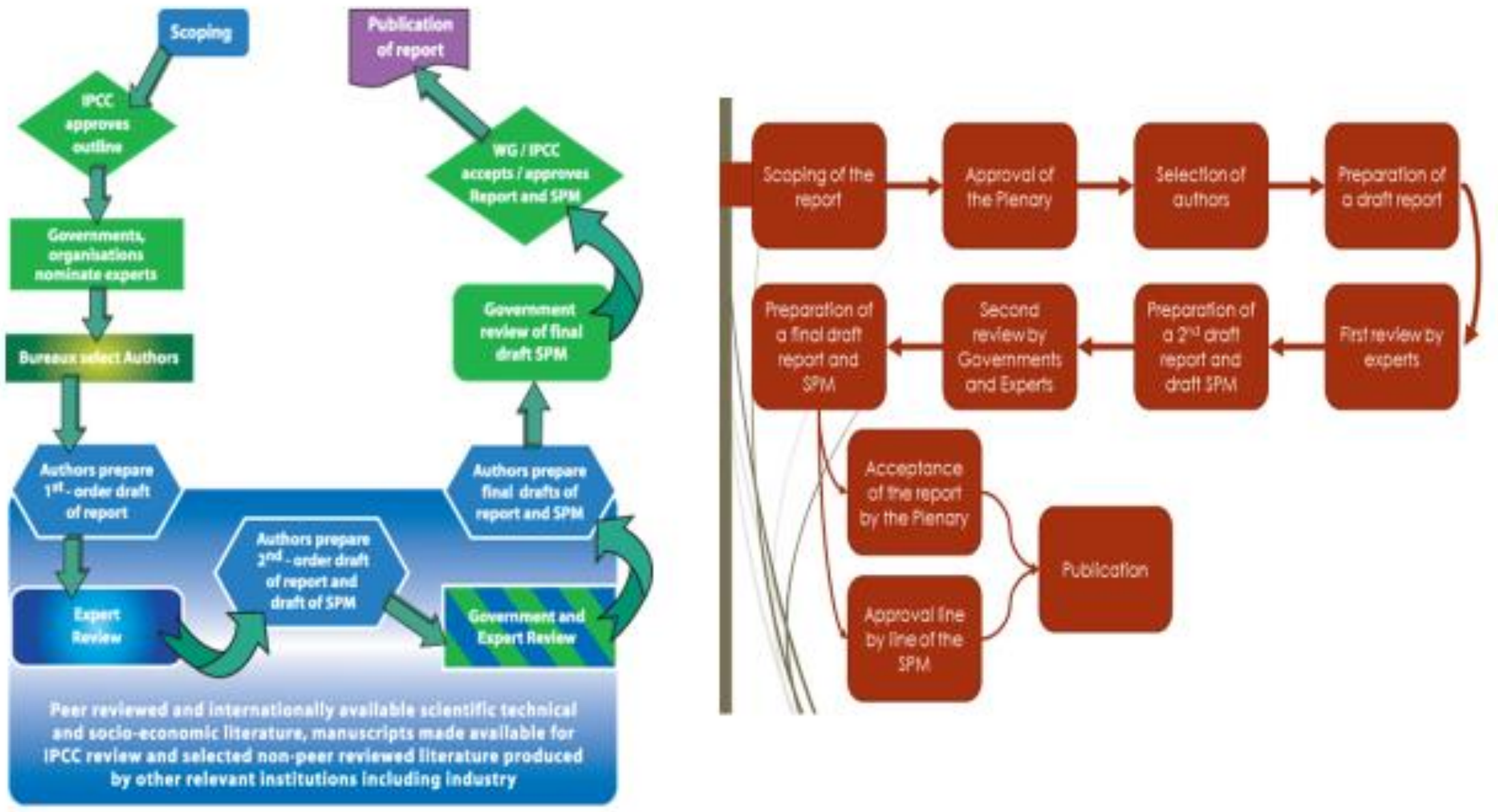

Figure 2: Writing and review procedures for IPCC and IPBES

Left diagram: IPCC process (source: Www.ipcc.ch)

Right diagram: IPBES process (simplified version by the author) 
B) Prevention and management of conflicts of interest

Dealing with conflicts of interest is of crucial importance in preventing a legitimacy and credibility crisis. Any report accused of bearing skewed information because of a conflict would be immediately rejected by both members and stakeholders. The existence of the conflict would be perceived as a breach of equity and justice and all related content of the report would be dismissed as being 'false' or at least not trustworthy.

IPCC has gone through a severe crisis in recent years. The mistakes that were pointed out in its report and the strong opposition of opponents led the Panel to reflect on its procedures. The mandate given to the Inter Academic Council to produce an independent review of the Panel led to numerous changes ${ }^{30}$, including the adoption of procedures for the prevention and management of conflicts of interest in $2011^{31}$.

These procedures were later incorporated in the IPBES framework during its third Plenary. This incorporation came at a crucial time when the Platform was already confronted with its first controversies. It was accused of promoting the interest of industry by allowing scientists involved in the pesticide production sector to be in charge of the drafting of chapters in the upcoming report on pollination ${ }^{32}$. The IPBES Secretariat responded to this accusation by stressing that the Platform procedures were suited to manage any situation that could lead to a conflict of interest ${ }^{33}$.

By analysing both procedures, we can once again see that the two institutions adopted similar approaches (see figure 3). Several definitions are taken from the IPCC framework and the

30 Inter Academic Council, 'Climate change assessments Review of the processes and procedures of the IPCC', IAC Secretariat, Amsterdam, 2010, 104 p.

31 See Report of the $33^{\text {rd }}$ Session of the IPCC, Abu Dhabi, United Arab Emirates, May 10-13, 2011, p. 4.

32 Hochkirch, A., McGowan, P., Van Der Sluijs, J., 'Biodiversity reports need author rules', Nature, vol. 516, 2014, p. 170.

33 Larigauderie, A., 'Pollinator assessment: IPBES responds on conflicts of interest', Nature, vol. 517, 2015, p. 271. 
overall mechanism is identical (establishment of a committee, requirement that experts fill in a form). However, caution is needed when claiming that these procedures are sufficient to ensure complete credibility. Indeed, the screening process of experts is far from being strict. The form the experts are required to fill in is very simple and request any information about, for instance, any previous professional ties that the expert may have had ${ }^{34}$. Moreover, the fact that these forms are kept secret by the Platform can be seen as a breach of transparency which might have an impact on the credibility of the process. Yet, total access to the form would be a breach of the experts' privacy. Finding balance on this issue is rather complicated and only time will tell if this rule of procedure is sufficient for efficient management of interests within the Platform. The fact remains that only IPBES is able to determine whether or not a conflict of interest is real or not, which might fuel dissent amongst observers.

\begin{tabular}{|l|l|l|}
\hline \multicolumn{1}{|c|}{$\mathrm{IPCC}^{35}$} & \multicolumn{1}{|c|}{ IPBES $^{36}$} \\
pay 2: The role of the-IPCC demands that it & s.2: The role of the Platform requires that \\
independence and bias in order to maintain & independence and bias in order to maintain \\
the integrity of, and public confidence in, its & the integrity of, and public confidence in, \\
products and processes. It is essential that & its products and processes. It is essential \\
the work of the IPCC is not compromised by & that the work of the Platform is not \\
any conflict of interest for those who & compromised by any conflict of interest for \\
execute it & those who execute it.
\end{tabular}

34 IPBES/3/L.6, Conflict of interest policy and implementation procedures, p. 8.

35 IPCC Conflict of interest policy, online at: www.ipcc.ch/organization/organization_procedures.shtml (last accessed: 30/06/2015).

36 IPBES/3/L.6, Conflict of interest policy and implementation procedures. 


\begin{tabular}{|l|l|l|}
\hline \$. 11: A 'conflict of interest' refers to any & \$. 11: For the purposes of this policy, any \\
current professional, financial or other & circumstances that could lead a reasonable \\
interest which could: i) significantly impair & person to question either an individual's \\
the individual's objectivity in carrying out his & objectivity, or whether an unfair advantage \\
or her duties and responsibilities for the & has been created, constitute a potential \\
IPCC, or ii) create an unfair advantage for & conflict of interest. \\
any person or organization. For the & \\
purposes of this policy, circumstances that & \\
could lead a reasonable person to question & \\
an individual's objectivity, or whether an & breated, \\
unfair advantage has been & \\
constitute a potential conflict of interest. & \\
These potential conflicts are subject to &
\end{tabular}

Figure 3: Partial comparison of the IPBES and IPCC conflict of interest policies.

The list of similarities between the two institutions could go on at length and this first section makes no claim to be exhaustive. The purpose of this short list is to simply illustrate the degree of influence the Panel has on the day-to-day work of the Platform.

If the examples used underline the relevance of the functional factor of institutional diffusion, the next section illustrates the influence of external factors in the shaping of the procedural identity of the Platform. 
II - Distinction and innovation - the creation of a distinct procedural identity.

As previously stated, political factors are to be taken into account when studying institutional diffusion. The introduction of this chapter recalled the marked differences in the context of each institution. These contexts bear different interests, powers and ideas and have a significant influence on how the IPBES rules of the procedure are constructed. The present section aims at discussing how this context led to the adoption of procedural innovations but was also the cause of unwelcomed modifications of rules transplanted from IPCC to IPBES.

\section{A - Ambitious procedural innovations}

The most salient innovations concern the way the Platform interacts with its members and stakeholders. In order to promote legitimacy and relevance, IPBES has adopted procedures guaranteeing collaboration and openness. In this respect, the two most remarkable procedural aspects are the working program drafting process on the one hand and the formal institutional linkages with other partners on the other.

\section{- Elaboration of the work programme}

The way the Platform work programme is established illustrates how the numerous expectations of the actors involved in the creation of IPBES are taken into account.

In the IPCC framework, the way the work programme is set remains constant from one period to another. Each evaluation cycle will discuss three aspects of climate change: 1 - the scientific evidence, 2- the impact, adaptation and vulnerability, and 3- mitigation. However, this consistency does not imply strict similarity between each Panel report. IPCC rules of procedure state that the exact outline of each evaluation cycle will be determined by experts from governments and observer organizations and Bureau members ${ }^{37}$. Once this outline is agreed by

37 Appendix A to the Principles Governing IPCC Work, Procedures for the preparation, review, acceptance, adoption approval and publication of IPCC reports, section 4.1 . 
the Panel Plenary, the evaluation process is applied as previously described. Based on this rationale, IPCC has published five reports since its creation (roughly one every 5-6 years) and has contributed to strengthening scientific consensus on the role of mankind in climate change, while also highlighting available solutions to reduce or cope with a phenomenon that is a dire threat to all societies ${ }^{38}$.

However, in the IPBES context, the work programme elaboration process allows for variation between evaluation cycles. Indeed, the exact content of the work programme is determined by the Multidisciplinary Expert Panel which relies on requests, suggestions and inputs from members, observers and stakeholders ${ }^{39}$. All of these requests are then synthesized by MEP in order to produce a first draft of the work programme that is subsequently discussed by members during the Plenaries and eventually adopted as the definitive work programme. In this synthesis process, priority is given to the requests of states while stakeholder requests, i.e. from international organizations, multilateral environmental agreements or NGOs, are considered as suggestions or inputs. This balance in favour of states is a logical repercussion of the intergovernmental aspect of the Platform. The outcome of this process resulted in the adoption of the first Platform work programme during the second Platform Plenary in $2014^{40}$. For instance, this supplementary step in drawing up a work programme, which does not exist in the IPCC framework, contributed to reaching an agreement on the regional scope of evaluations that the Platform intends to produce in the upcoming years, or even on the elaboration of a report on land degradation and restauration.

38 IPCC, Climate Change 2014: Synthesis Report. Contribution of Working Groups I, II and III to the Fifth Assessment Report of the Intergovernmental Panel on Climate Change, Core Writing Team, Pachauri, R.K. and Meyer, L.A. eds., IPCC, Geneva, Switzerland, 2014, 151 p.

39 IPBES-1/3, Procedure for receiving and prioritizing requests put to the Platform.

40 IPBES-2/5, Work programme for the period 2014-2018. 
The diverse requests received by the Platform illustrate how the current biodiversity and ecosystem crisis has several translations within different levels and sectors (see figure 4).

\begin{tabular}{|c|c|c|}
\cline { 2 - 3 } \multicolumn{1}{c|}{} & Number of actors & $\begin{array}{c}\text { Number of requests, } \\
\text { suggestions and inputs }\end{array}$ \\
\hline States & 10 & 36 \\
\hline Multilateral Environmental & 4 & 13 \\
\hline Agreements & & 30 \\
\hline Stakeholders & 10 & \\
\hline
\end{tabular}

Figure 4: Overview of requests, suggestions and inputs received by the Platform for

$$
\text { elaboration of the first work programme }{ }^{41}
$$

States often have to deal with specific issues that can considerably vary between regions. For instance, France formulated a request on the protection and sustainable use of marine ecosystems, whereas China requested an evaluation on biodiversity and ecosystems in postdisaster areas. The Convention on Migratory Species requested an assessment of the ecological function of migratory species, and other multilateral environmental agreements also issued a request to the Platform to work on their respective thematic foci. Stakeholders had various suggestions, from the establishment of a long-term framework for biodiversity data provision and use (request by the Global Biodiversity Information Facility) to actions to strengthen the use of scenarios and models in assessments (suggestion by the International Council for Science).

41 See IPBES/2/INF/9, Supporting documentation on the prioritization of requests, inputs and suggestions put to the Intergovernmental Science-Policy Platform on Biodiversity and Ecosystem Services. 
This procedure highlights the Platform's efforts to take the wide range of expectations from its members and stakeholders into account. By doing so, the work programme is likely to be perceived as highly relevant. Moreover, states are not the only actors who expect the Platform to have useful outcomes. Biodiversity-related conventions, international organizations, NGOs and research institutions have the same expectations. Even though their inputs are not a priority when drafting the work programme, they are nevertheless taken into account by MEP. All of these procedural elements, if applied correctly, will be a strong asset for the relevance of the Platform. Hopefully the Platform will receive more requests, suggestions and inputs when the time comes to draw up a second work programme. Indeed, for an intergovernmental institution with over a hundred member states, it is unfortunate that only 10 states have made requests. Although the work programme was discussed within the members and is therefore the result of consensus, higher member involvement in this first phase would increase the legitimacy and relevance of the next work programmes.

As illustrated by the work programme elaboration process, IPBES has links with numerous actors working on biodiversity and ecosystems governance. This important feature led to the adoption of several decisions to establish the Platform external relations management procedures.

- Formal ties with other actors of biodiversity and ecosystem governance.

The decisions adopted in 2015 illustrate the extent to which the implementation of the work programme is expected to be a collaborative effort. The place allocated for stakeholders within the Platform is a salient illustration of this aspect ${ }^{42}$. Indeed, member states invite stakeholders to organize themselves within an open-ended network in order to support the work of the Platform by helping with the nomination of experts or liaising with hard to reach stakeholders.

42 IPBES/3/L. 15, Revised Stakeholder Engagement Strategy. 
This call for greater involvement of the protean community of stakeholders is both praiseworthy and necessary as it tends to ensure credibility and legitimacy ${ }^{43}$. Even if this aspect cannot be perceived as procedural according to our understanding of the term, one aspect of its implementation is linked to the procedures for the establishment of strategic partnerships. Indeed, the decision on the stakeholder engagement strategy calls for the adoption of a strategic partnership during the next Platform Plenary. In the context of our analysis, the rules of procedure adopted on this topic highlight how crucial the status of other actors of biodiversity and ecosystem governance is for IPBES ${ }^{44}$.

Strategic partnerships have several purposes, one of which is the creation of technical support units. Like IPCC, IPBES relies on these TSUs in charge of coordinating activities linked to the production of its deliverables. IPBES has already established such units with the support of UNESCO on the theme of indigenous and local knowledge ${ }^{45}$. This practice is yet another example of institutional transplantation from IPCC. However, IPBES is innovative on the administrative aspects of these $\mathrm{TSUs}^{46}$, which are established through very specific agreements which clearly state both the precise mandate of the unit and the responsibilities of the Platform and the unit. This aspect should allow for a more effective TSU governance in the coming years.

However, strategic partnerships are not only meant to establish TSUs. The decision on strategic partnerships also calls for formal collaboration with the other major multilateral environmental agreements in the field of biodiversity and ecosystems. Partnerships should facilitate mainstreaming of the Platform and MEA activities and avoid redundancy. This is also a way

43 However, stakeholders are left to their own devices to establish the open-ended network. Because of their number and the absence of a clear and centralized centre of organization, it is hard to determine at this point what the open-ended network will look like.

44 IPBES/3/ L.8, Strategic Partnerships.

45 IPBES/3/INF/13, Report on the institutional arrangements established to operationalize technical support.

46 As illustrated by the discussion on this aspect within IPCC. See IPCC-XLI/Doc. 4, Consideration of recommendations by the task force group on Future Work of IPCC, p. 5. 
for the Platform to ensure the relevance of its activities towards MEAs ${ }^{47}$. On the other hand, in the IPCC context, the Panel has no formal framework of collaboration with UNFCCC. This issue has been addressed several times within IPCC and has yet to be definitively resolved ${ }^{48}$.

In its application of the decision on strategic partnership, IPBES relies on several types of legal instruments in order to formalize its relations with other institutions. Memorandums are frequently used. These pseudo-contracts remain a mystery in the field of legal studies ${ }^{49}$. Written in the form of a contract, they do not possess any legal strength and only allow for the formalization of cooperation principles between several actors. Yet, their contractual aspect often includes very precise articles on interpretation, entry into force, settlement of disputes and even denunciation.

The use of such instruments, which elude classical legal conceptions yet are so close to them, adds a supplementary dimension to the way IPBES interacts with its institutional environment as compared to IPCC. This is a very interesting example of how a procedural requirement translates into the use of quasi-legal or para-legal instruments. It will be important to check on a practical level how far this aspect will influence future development of the Platform.

In many respects, IPBES is innovative when it comes to its interaction with other actors of the regime. These innovations can be understood as a consequence of the very rich institutional landscape within which the Platform is established. However, besides those positive innovations, some worrying modifications have been made in the transplanted IPCC procedures that may undermine the credibility of the Platform.

47 See Memorandum of Cooperation between the Secretariat of the Convention on Biological Diversity and the Secretariat of the Intergovernmental Science-Policy Platform on Biodiversity and Ecosystem Services, Pyeong Chang, October 9, 2014, available online at: www.cbd.int/doc/agreements/agmt-ipbes-2014-10-09-mou-en.pdf (last accessed: 30/06/2015).

48 See IPCC-XLI/Doc. 5, Chairman's Vision Paper on the Future of the IPCC.

49 Scott, K., 'International environmental governance: Managing fragmentation through institutional means', Melbourne Journal of International Law, vol. 12, 2011, pp. 177-216, p. 192. 
B - An unfortunate change in the expert selection process

During the second Platform Plenary, criteria for the selection of experts were at the centre of a heated debate ${ }^{50}$. This question has a very important strategic aspect that led to an opposition between two rationales. On the one hand, some states, including China and Argentina, wanted total control over the nomination of experts, thus keeping any expert nominated by relevant institutions that did not have a formal endorsement by the state out of the process. This condition would put IPBES in a very different position than IPCC, where experts are nominated by both member states and relevant institutions ${ }^{51}$. On the other hand, European Union states, with support from the attending observers, wanted a process similar to that of IPCC in order to nominate experts most able to ensure satisfactory implementation of the work programme.

The push towards state control over the nomination of experts was one of the crucial points of the second Plenary. The outcome of negotiations on this point gave rise to a convoluted solution whose application is not straightforward.

MEP members, nominated by member states according to a geographical balance ${ }^{52}$, have the responsibility of selecting experts in charge of the drafting each work programme report. They do so by relying on a list of experts nominated by both governments and relevant institutions. However, the selection has to respect a very precise balance that calls for a quota of $80 \%$ of government nominated experts and $20 \%$ of experts from relevant institutions ${ }^{53}$. Following this rule of procedure, if a report requires 100 experts to be drafted, 80 of them have to be government nominated.

50 Pesche, D. et al., 'Le Consensus d'Antalya: les avancées de la Plateforme Intergouvernementale scientifique et politique sur la biodiversité et les services écosystémiques (IPBES)', Nature Science et Société, vol. 22, n³, 2014, pp. 240-246.

51 Appendix A to the Principles Governing IPCC Work, Procedures for the preparation, review, acceptance, adoption approval and publication of IPCC reports, section 4.3.2.

52 IPBES-2/2, Multidisciplinary Expert Panel.

53 IPBES-2/3, Procedures for the preparation of the Platform's deliverables, section 3.6.2. 
This procedural requirement illustrates the extent of the stakes associated with biodiversity and ecosystems, most notably state sovereignty and the South/North divide. For instance, states in favour a higher control over the expert selection process claimed that it was of the highest importance that evaluations concerning their biodiversity and ecosystems be led by their own experts. This situation clearly demonstrates how difficult it is to focus on scientific aspects alone in international negotiations even when the rights and obligations of states are not directly concerned. In summary, this is a case of diffusion from IPCC to IPBES but with a modified outcome due to the ideas and interests of specific states in the Platform context.

This procedural aspect leads to obvious practical issues. Its strict application makes it hard to achieve the required number of selected experts. The IPBES Secretariat highlighted this problem in its report on implementation of the work programme and suggested to member states that they should reconsider this procedural rule ${ }^{54}$. For most European states, this 80/20 requirement does not constitute a severe obstacle for the nomination and selection of experts as they often closely collaborate with their own national institutions when nominating experts. However, in other regions, most notably Eastern Europe, this rule of procedure hinders the selection process. For instance, when a group of states has not nominated a sufficient number of experts to reach the required $80 \%$, it is necessary to call for additional nominations within this group. These 'default' nominations can be a drawback for the credibility of the Platform as the involved experts might not be as qualified or motivated as the stakeholders and observers hope them to be. This can also be a threat to the quality of the deliverables in which those experts were involved.

54 IPBES/3/2, Implementation of the Work Programme for 2014-2018, p.4, "Considering revisiting the requirement of $80 \%$ of selected experts having to come from government nominations to make it a less stringent requirement. This would potentially reduce the need for requesting governments for additional nominations". 
Moreover, considering the fact that the nomination of experts is already influenced by the heavy pro bono workload that the involvement in the IPBES process represents ${ }^{55}$, one can only be sceptical towards this procedural aspects that may even further limit the involvement of qualified and willing experts. As such, this rule of procedure appears to be in contradiction with state expectations for the Platform. Indeed, during the second and third Plenaries, on numerous occasions states pointed out that the work programme may be too ambitious and too heavy on IPBES. Yet, even though they were fully aware of this aspect, several of their decisions on the budget or the procedures ended up being more of an impediment than a support for the Platform. The fact that they did not wish to change the $80 / 20$ requirement for the selection of experts illustrates this ambiguous discourse by Platform members who ask so much of it while reducing its capacity. We will have to wait until the end of the first work programme to determine whether or not this analysis is too pessimistic, but from a theoretical standpoint, this procedural adaptation is a cause for concern.

$$
* * * * *
$$

This chapter has described a situation that is simply a logical reflection of the external elements which have shaped the establishment of the Platform. To overlook the IPCC case would have meant overlooking the wealth of experience amassed over time and by weathering the storms of controversy. How could one not acknowledge this institution when the initial idea for the creation of the Platform was to form an 'IPCC for biodiversity'? Not taking these precious lessons into account would have been a serious mistake. The current IPBES rules of procedure are, as such, very similar to those of IPCC. This does not mean however that IPBES is bound to simply be copy of IPCC.

\footnotetext{
55 IPBES/1/INF/15, Preliminary review of the motivations for participating in Platform assessments.
} 
IPBES is innovative in several ways. Although this chapter was focused on its procedure, the Platform also adopted some very interesting governance tools, such as the 'conceptual framework $^{56}$. This framework illustrates how IPBES differentiates itself from IPCC not only by its procedure but also by the concepts upon which its work relies. Whereas IPCC is currently working on how to integrate traditional and local knowledge in its work, this theme was integrated very early in the IPBES framework via the conceptual framework. Even though this framework is not within the scope of our analysis, illustrating how distinct IPBES is from IPCC would have been incomplete without referring to this aspect.

Some observers consider that currently IPBES activities are too similar to those of IPCC and that it should seek to differentiate itself more ${ }^{57}$. This opinion is based on the fact that half of the IPBES budget is allocated to the evaluation function of the Platform, whereas the other half is divided among its other functions. However, considering the rules of procedure of the Platform and its context, it could be expected that in the years to come IPBES will develop in a very different way from IPCC. Now that the Platform has 'started working', it will forge its own identity. Moreover, the two institutions actually have started exchanging on several topics and the purpose of these exchanges is not only for IPBES to learn from IPCC. During its recent Plenary in Nairobi, IPCC took the practice of IPBES concerning its TSUs into account and suggested that its members should adopt new procedures based on this model ${ }^{58}$. Even though this proposal was turned down due to the lack of perspective on the long term application of these rules of procedures ${ }^{59}$, it goes to show that future relations between these two institutions will surely be based on mutual learning. This perspective of coevolution is a good sign as it will

56 IPBES/2/4, Conceptual Framework for the Intergovernmental Science-Policy Platform for Biodiversity and Ecosystem Services. For a detailed analysis, see Diaz, S. et al., 'A Rosetta Stone for Nature's Benefits to People', PLOS Biology, vol.13, ${ }^{\circ} 1,2015$, pp. 1-8.

57 Brooks, T.M., Lamoreux, J.F., Soberon, J., 'IPBES $\neq$ IPCC', op. cit.

58 IPCC-XLI/Doc. 4, Consideration of the recommendations by the task force group on Future Work of the IPCC, p. 5.

59 Earth Negotiation Bulletin, vol. 12, $\mathrm{n}^{\circ}$ 67, 2015. 
participate in elevating the work standards and also contribute to ensuring the highest credibility, legitimacy and independence.

Yet, the Platform is not above criticism. The criteria adopted for the selection of experts, its relatively low budget and heavy workload may hinder implementation of its work programme. As such, before putting forward hypotheses on the future influence of the Platform on IPCC, it is essential to first follow its initial process and assess its outcome. The adoption of its first reports in February 2016 will be a first trial and will pave the way for its future development.

Although this chapter has analyzed the influence of various external elements, it cannot offer any definitive proposals on the future of the Platform. It would be safe to assume that it will forge its own institutional identity since its mandate and procedures are obviously distinct from its model. However, considering the very ambitious work programme set by its members and the numerous obstacles it has to overcome, the prospects give cause for concern. The next meeting in Kuala Lumpur may provide answers to all of these interrogations.

\section{REFERENCES}

Agrawala (S.), 'Structural and process history of the IPCC', Climate Change, vol. 39, 1998, pp. 621-642.

Beck (S.) et al., 'Towards a reflexive turn in the governance of global environmental expertise: the case of the IPCC and the IPBES', Gaya, vol.23, n², 2014, pp. 80-87.

Brooks, T.M., Lamoreux, J.F., Soberon, J., 'IPBES $\neq$ IPCC', Trends in ecology and evolution, vol. $29, \mathrm{n}^{\circ} 10,2014$, pp. 543-545.

Hochkirch, A., McGowan, P., Van Der Sluijs, J., 'Biodiversity reports need author rules', Nature, vol. 516, 2014, p. 170.

Koetz, T., Farrell, K., Bridgewater, P., Building better science-policy interfaces for international environmental governance: assessing the potential within the IPBES, International Environmental Agreements: Politics, Law and Economics, vol. 12, n¹, 2012, pp. $1-21$. 
Larigauderie, A., 'Pollinator assessment: IPBES responds on conflicts of interest', Nature, vol. 517, 2015, p. 271.

Maljean-Dubois S. 'La Plateforme Intergouvernementale Scientifique et Politique sur la Biodiversité et les Services Ecosystémiques (IPBES)', Journal International de Bioéthique, vol. $35, \mathrm{n}^{\circ} 1,2014$, pp. 55-73.

Orsini, A., Morin, J.F., Young, O., 'Regime Complexes: A Buzz, a Boom, or a Boost for Global Governance?', Global Governance, vol. 19, 2013, pp. 27-39.

Ovodenko, A., Keohane, R., 'Institutional diffusion in international environmental affairs', Institutional Affairs, vol. 88, n³, 2011, pp. 523-541.

Pesche, D. et al., 'Le Consensus d'Antalya: les avancées de la Plateforme Intergouvernementale scientifique et politique sur la biodiversité et les services écosystémiques (IPBES)', Nature Science et Société, vol. 22, n³, 2014, pp. 240-246.

Rausitalia, K., Victor, D., 'The Regime Complex for Plant Genetic Ressources', International Organization, vol. 58, n², 2004, pp. 277-309.

Scott, K., 'International environmental governance: Managing fragmentation through institutional means', Melbourne Journal of International Law, vol. 12, 2011, pp. 177-216. 